\title{
Forging the Future of Food and Nutrition Education
}

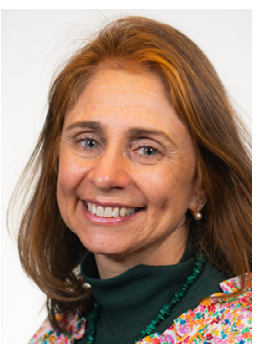

In her final JNEB presidential editorial, Jennifer Wilkins described how the COVID19 pandemic presents challenges and opportunities. ${ }^{1}$ As I write this in early June, both the pandemic and protests for racial justice dominate the news. These crises have exacerbated the challenges we already faced: ecological threats on a planetary scale, the fragility of centralized and concentrated food systems, racial inequities in food access and health, and a food supply dominated by ultra-processed foods.

Times of disruption are moments to reflect, redirect, and rebuild. Food and nutrition education can empower people to demand healthy, just, and sustainable food by disrupting the status quo. Let's roll up our sleeves and forge the future by elevating what I am calling the 5Rs of food and nutrition education: richness, resolve, recognition, relevance, and resilience.

\section{RICHNESS}

The Program in Nutrition at Teachers College, Columbia University proudly professes that we cover everything "from the farm to the fat cell." That breadth beautifully describes the richness of our field. For example, we need to understand how different farming systems impact public and planetary health, ${ }^{2}$ and how water systems connect to human health. ${ }^{3}$ We need to acknowledge that black and indigenous people have had their farmland unjustly taken from them and support reparations. ${ }^{4}$ We need to address food injustice. ${ }^{5}$ With a broad focus for food and nutrition education we can be are part of creating a rightsbased approach to food security to provide adequate, nourishing food and equitable access for everyone. ${ }^{6}$

\section{RESOLVE}

We need to bring more racial and ethnic diversity to our mostly white profession and address the systemic barriers that students of ethnic minorities face to accessing education and professional opportunities. Nutrition educators, most of whom are white, need to learn how our cultural frame of reference influences our practice, research questions and methods, and advocacy. With a greater deeper cultural self-awareness, we can resolve as a Society to move beyond seeing white culture as the assumed norm against which other cultures are compared. ${ }^{8}$

\section{RECOGNITION}

We recognize that nutrition education is complicated by myriad cultural, community, and societal aspects of humans' lives. This complexity also makes our field dynamic and exciting. We need to faithfully incorporate intra- and interpersonal factors, racial equity, food system sustainability, as well as policy, systems, and environmental influences into all of our research, policy, and practice. ${ }^{2,8-10}$

\section{RELEVANCE}

The COVID-19 pandemic has elevated the importance of healthy diets in fighting infectious diseases and preventing chronic diseases, now referred to as underlying conditions. ${ }^{1,12}$ Nutrition educators are at the forefront of helping people achieve healthy diets. Yet, the 2020 -2030 Strategic Plan for NIH Nutrition Research is silent on funding for the effectiveness of nutrition education. ${ }^{13}$ We need louder and clearer voices to elevate the critical role of nutrition education research, policy, and practice.

\section{RESILIENCE}

Nutrition educators have grit. We are flexible. We adapt. We can make this time of upheaval change into an opportunity by forging new directions for the future of our field, and we can do it together.

I am honored to be SNEB's President for the next year and I am excited to work with you.

Pamela Koch, EdD, RD President, Society for Nutrition Education and Behavior

\section{REFERENCES}

1. Wilkins J. Challenges and opportunities created by the COVID-19 pandemic. J Nutr Educ Behav. 2020;52:669-670.

2. Rose D, Heller MC, Roberto CA. Position of the Society for Nutrition Education and Behavior: the importance of including environmental sustainability in dietary guidance. $J$ Nutr Educ Behav. 2019;51:3-15.

3. Cody MM, Stretch T, Academy of Nutrition and Dietetics. Position of the Academy of Nutrition and Dietetics: food and water safety. J Acad Nutr Diet. 2014;114:1819-1829.

4. International Commission of Jurists. The Right to a Remedy and Reparation for Gross Human Rights Violations: A Practitioners' Guide. Geneva, Switzerland: International Commission of Jurists; 2018.

5. Hayes C, Carbone R. Food Justice: What is it? Where has it been? Where is it going? J Nutr Disorders Ther. 2015;5:1000179.

6. Anderson M. Beyond food security to realizing food rights in the US. J Rural Stud. 2013;29:113-233.

7. Riediger ND, Kingson O, Mudryj A, et al. Diversity and equity in dietetics and undergraduate nutrition education in Manitoba. Can J Diet Pract Res. 2019;80:44-46

8. Setiloane KS. Beyond the melting pot and salad bowl views of cultural diversity: advancing cultural diversity education of 
nutrition educators. $J$ Nutr Educ Behav. 2016;48:664-668.

9. McIsaac JLD, Spencer R, Stewart M, et al. Understanding system-level intervention points to support school food and nutrition policy implementation in Nova Scotia, Canada. Int J Environ Res Public Health. 2019;16:712.

10. Bowen DJ, Barrington WE, Beresford SAA. Identifying the effects of environmental and policy change interventions on healthy eating. Annu Rev Public Health. 2015;36:289-306.

11. Fan Y, Zhang Y, Tariq A, et al. Food as medicine: a possible preventive measure against coronavirus disease (COVID-19) [published online ahead of print May 28, 2020]. Phytother Res. https://doi.org/10.1002/ ptr.6770.
12. Gasmia A, Noorb S, Tippairotec T, et al. Individual risk management strategy and potential therapeutic options for the COVID-19 pandemic. Clin Immunol. 2020;215: 108409.

13. NIH Nutrition Research Taskforce. 2020-2030 Strategic Plan for NIH Nutrition Research. Bethesda, MD: National Institutes of Health; 2020.

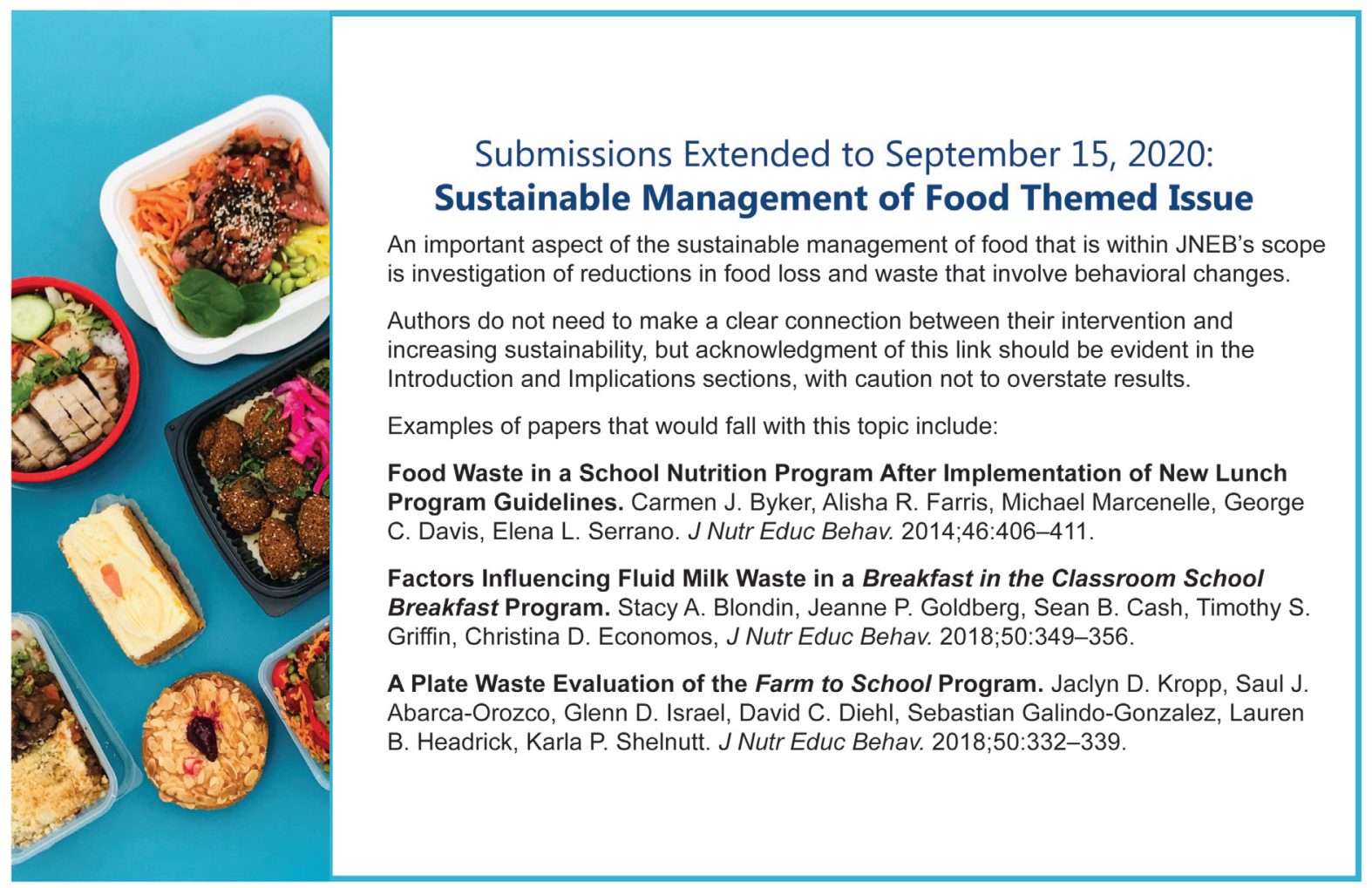

